\title{
The effect of acceptance and commitment based on the fear of delivery pain- A randomized educational trial study
}

\author{
${\text { Fahimeh } \text { Zarei }^{1}(\mathbb{D})}_{\text {Katayon Vakilian }^{1}}{ }^{(D)}$ Abed Majidi $^{2}$ (D)
}

\begin{abstract}
Background and Aim: Pregnancy due to physiological and psychological changes can affect the mental health of mothers.

This study aims to investigate the Approach of acceptance and commitment based on the fear of delivery pain.

Materials and Methods: This study was a randomized educational trial with a commitment-based treatment approach that was performed on pregnant women in Arak in 2016-2017. After obtaining written consent forms, 42 subjects were selected through the available sampling method. Subjects were grouped in the intervention group (ACT) and in the control group. Eight 90-minute sessions were held for 8 consecutive weeks of counseling Fear of delivery pain at 10 and one month after the intervention was measured in 2 groups by the Likert scale of pain (1-7) score. Data analysis was performed through repeated measure ANOVA by using SPSS (Version 18).

Results: Results showed that the mean pain immediately after the intervention was $2.52 \pm 2.20$ in the intervention group and $4.66 \pm 1.80$ in the control group. Which is a month later in the intervention group compared to the control group had a significant decrease ( $3.52 \pm 1.81$ vs. $4.52 \pm 2.30)(\mathrm{P}=0.001)$.

Conclusion: In this study, counseling with the approach of acceptance and commitment reduction the fear of delivery pain, which is the most important reason for choosing cesarean section in women, Therefore, it seems that empowering midwives to counseling approaches can be useful to improve maternal care during pregnancy, especially in the administration of delivery preparation classes.
\end{abstract}

Key Words: Counseling, Fear of Delivery, Mental Health, Pregnancy Care, Reproductive Health

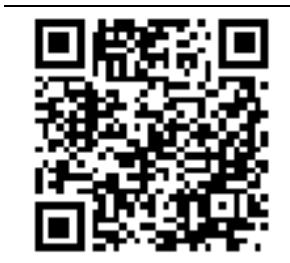

Citation: Zarei F, Vakilian K, Majidi A. [The effect of acceptance and commitment based on the fear of delivery pain- A randomized educational trial study]. J Birjand Univ Med Sci. 2020; 27(3): 241-250. [Persian].

DOI http://doi.org/10.32592/JBirjandUnivMedSci.2020.27.3.103

Received: February 19, 2020

Accepted: July 1, 2020

\footnotetext{
${ }^{1}$ Nursing and Midwifery Department, Arak University of Medical Sciences, Arak, Iran

${ }^{2}$ Counseling Department, Isfahan University, Isfahan, Iran
}

Corresponding author; Nursing and Midwifery Department, Arak University of Medical Sciences, Arak, Iran.

Tel: +988634173505 Fax: $+988634173524 \quad$ Email: dr.kvakilian@arakmu.ac.ir 


\title{
تأثير رويكرد مبتنى بر يذيرش و تعهد بر ترس از درد زايمان - يك مطالعه كار آزمايى آموزشى تصادفى نديه
}

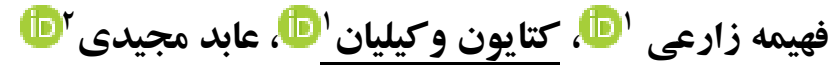

\section{جكيله}

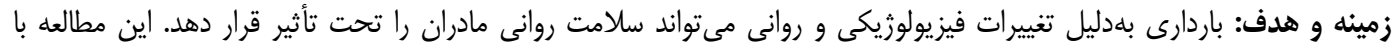

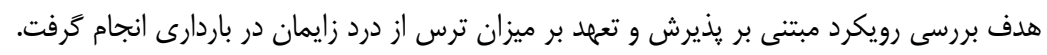

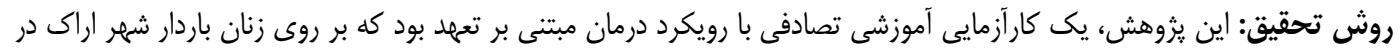

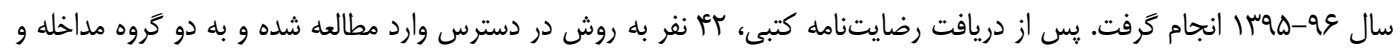

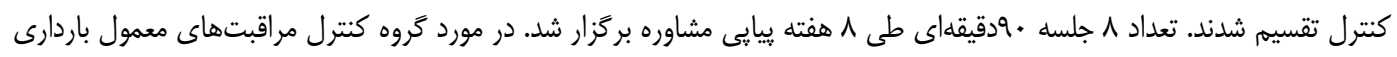

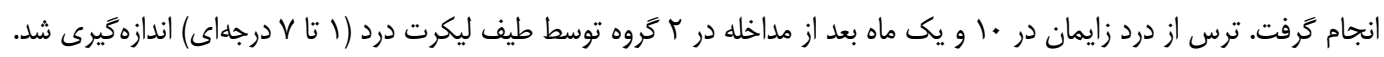

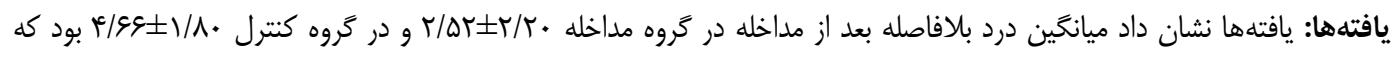

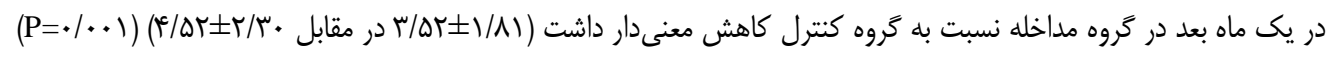

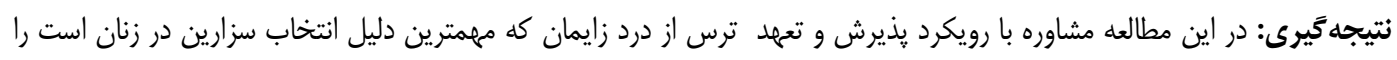

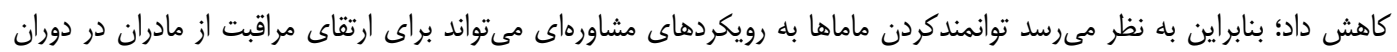

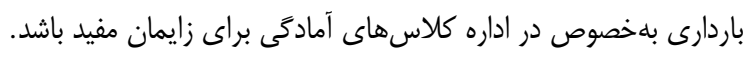

$$
\begin{aligned}
& \text { وازههاى كليدى: مشاوره، ترس زايمان، سلامت روان، مراقبت باردارى، بهداشت بارورى }
\end{aligned}
$$

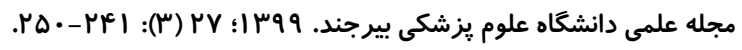

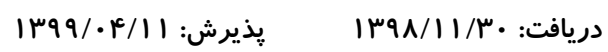

أبروه يرستارى و مامايى، دانشكاه علوم يزشكى اراك، اراك، ايران.

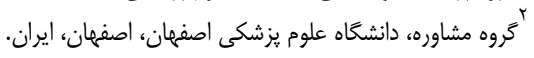

نويسنده مسؤول؛ دانشكده يرستارى و مامايى، دانشكاه علوم يزشكى اراك، اراك، ايران.

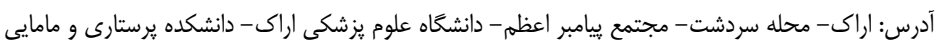

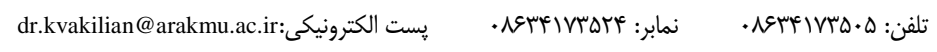


نشان مىدهد كه روشهاى مشاورهاى مىتواند در كاهش اين

مقدمه ترس و نكرانىها كمك كننده باشد.

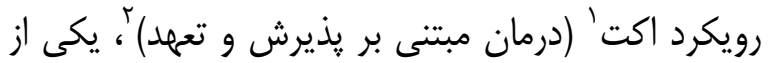

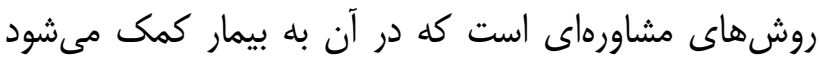

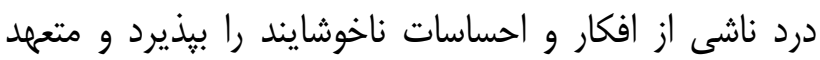

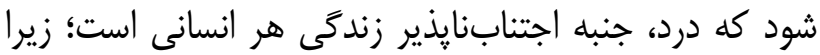

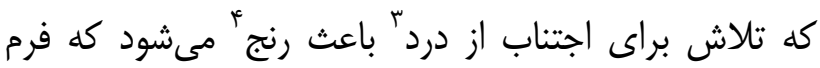

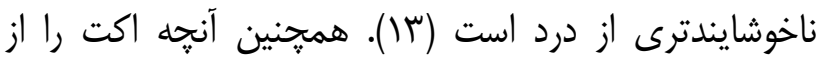
ساير روشهاى درمانى مجزا مى كند استفاده از استعارههاست

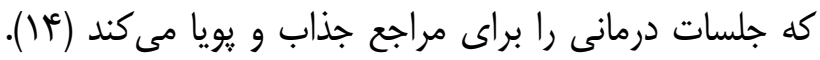

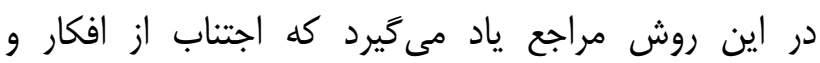

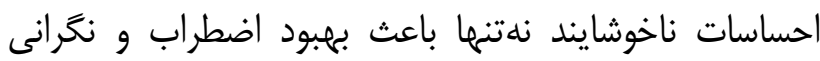

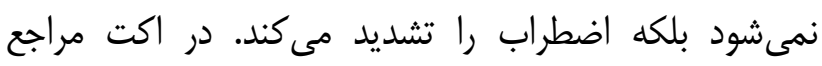

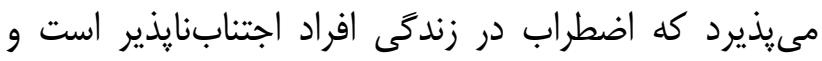

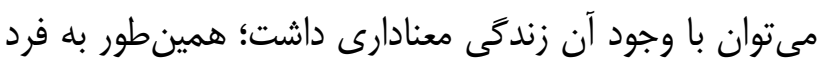

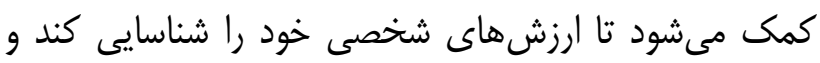

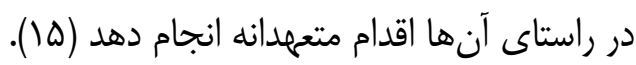

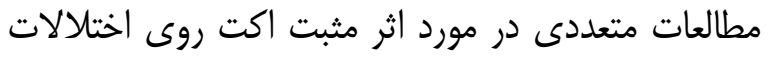
اضطرابى، اختلالات وسواسى جبرى (91)، اختلال اضطراب

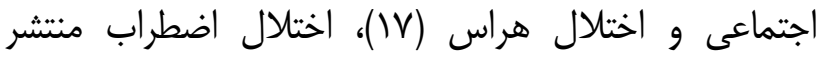

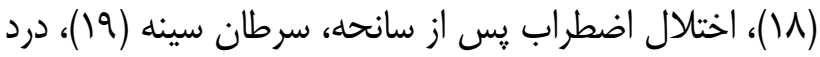

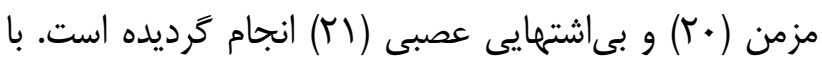

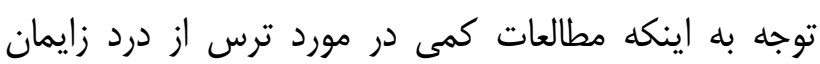

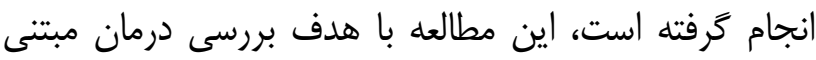
بر يذيرش و تعهد بر ميزان ترس از درد زايمان انجام كَرفت.

\section{روش تحقيق}

اين مطالعه، يك كارآزمايى آموزشى تصادفى بود. در اين

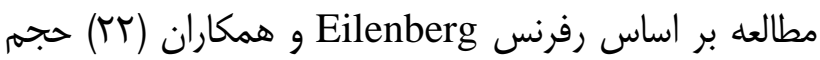

\footnotetext{
${ }^{1} A C T$

${ }_{3}^{2}$ Acceptance commitment therapy

${ }_{4}^{3}$ pain

suffer
}

ترس از زايمان به روشهاى مختلفى تعريف شده است و

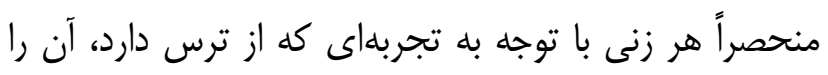

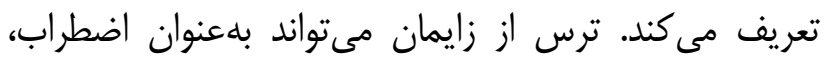
فوبياى آشكار، كابوس شبانه، مشكلات جسمانى، مشكل آنسان

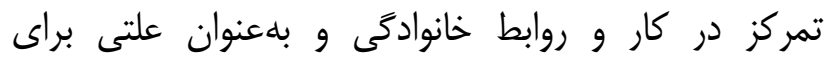

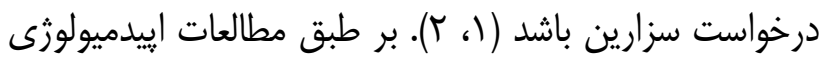

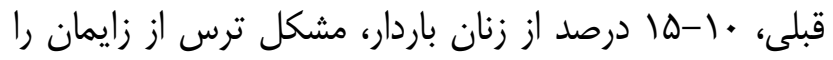

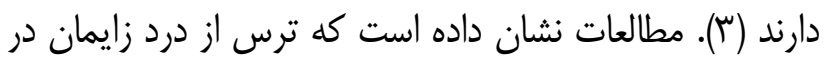

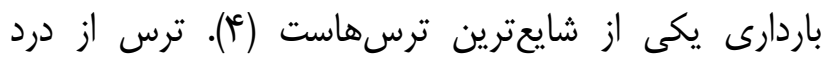

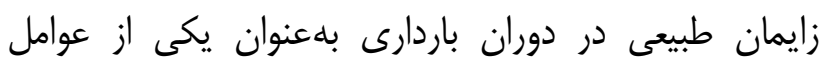

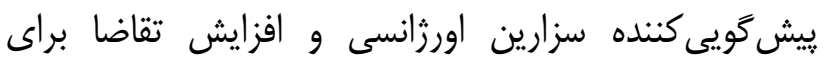

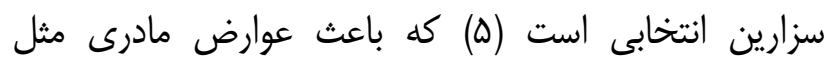

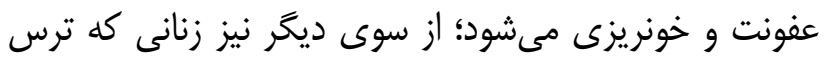

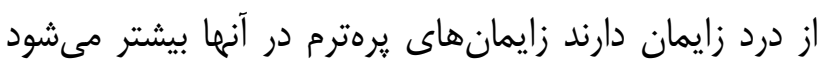

مطالعات متعدد در ايران نشان داد كه مهمترين علت تمايل زنان به زايمان سزارين، ترس از درد شديد ناشى از

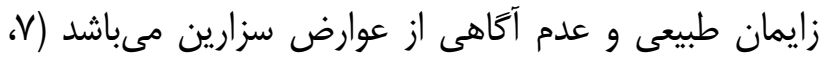

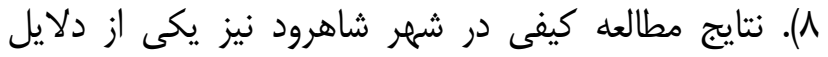

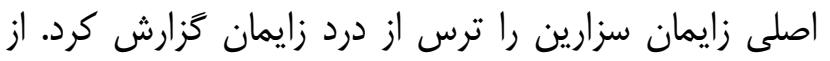

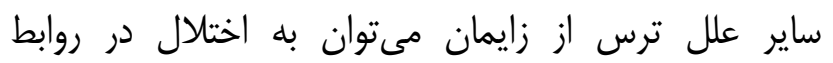

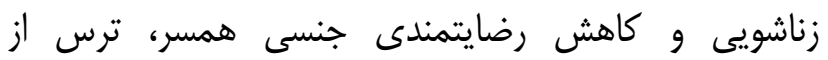

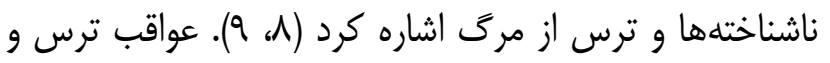

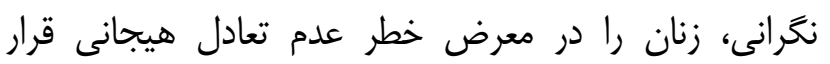

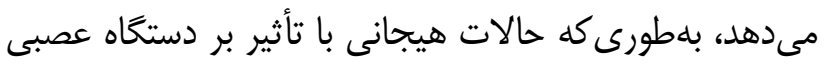
مادر سبب آزادشدن برخى مواد شيميايى مثل استيل كولين و والئ

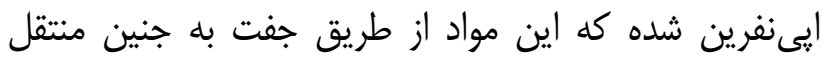

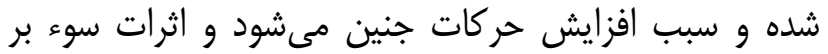

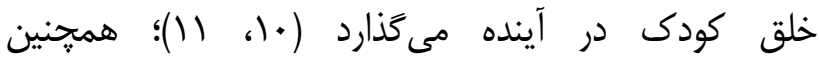

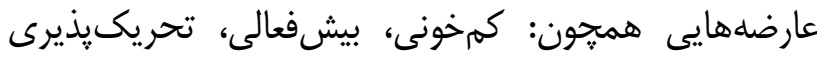
زياد و بدغذايى در هنين كودكانى بيشتر است (I) (I). مطالعات 
اب نفره كنترل و مداخله (گروه اكت) تخصيص ييدا كردند و به روش تصادفى در يكى از گروهها قرار گرفتند.

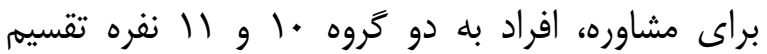

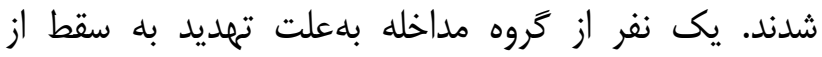

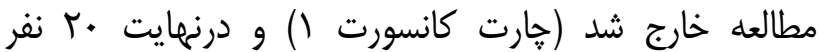
جلسات مطالعه را تكميل كردند. كلاسها توسط دانشجوى مشاوره ارشد مامايى كه دوره اكت را كذرانده بود اداره شدند. محل تشكيل كلاسها در بيمارستان جايى كه مشاور در آن مشغول به كار بود اجرا شد. ارزيابى ترس قبل از جلسات، در ب عروه انجام شدام شد.

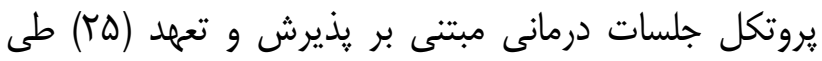

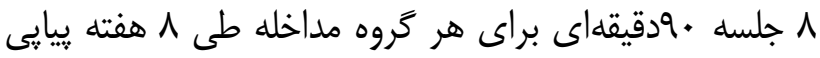

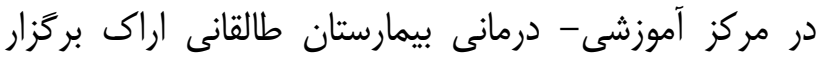

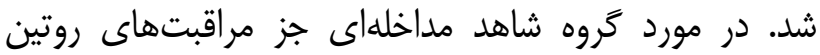

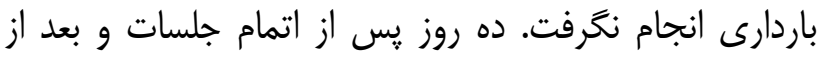
يك ماه، دوباره ترس از درد زايمان بررسى شد؛ همجِّنين

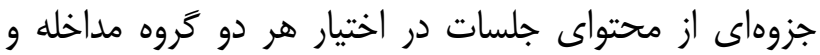
كنترل قرار

خلاصه محتواى جلسات در جدول يك آورده شده است. لازم به ذكر است كه هر جلسه مداخله، با ارائه تكاليف و دادن جلن أندات

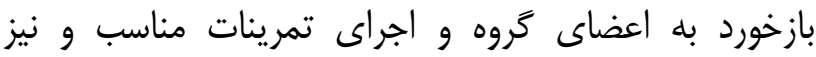
مرورى بر جلسات قبل سازماندهى شد.

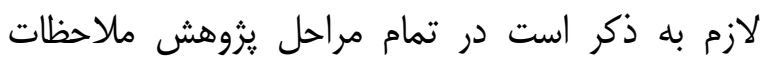

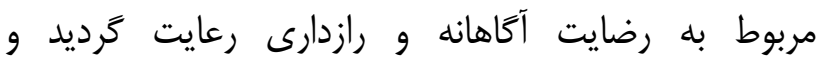

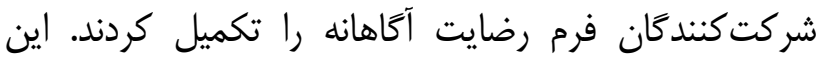
مطالعه توسط كميته اخلاق دانشگاه علوم يزشكى با كد رداه IR.ARAKMU.REC.1395.230 تأييد شد و در مركز كارآزمايى بالينى با كد IRCT2016092429949N1 ثبت كرديد.
نمونه براى هر گروه آ نفر برآورد شد و مطالعه بر روى بع زن باردار مراجعه كننده به مراكز بهراشتى شهر اره اراى (ايران)

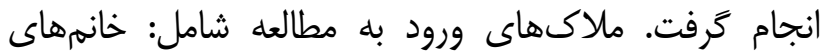

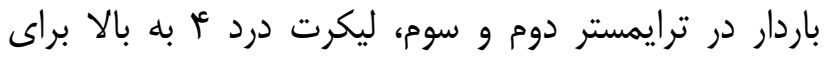

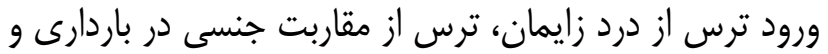
تصوير ذهنى منفى از بلن در باردارى، تكىقلويى، عدم ابتلا به بيمارىهاى مزمن، عدم سابقه و يا ابتلا به سقط، علائم

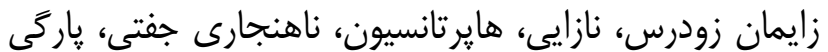

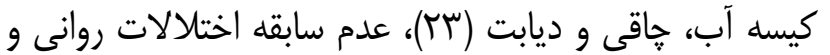

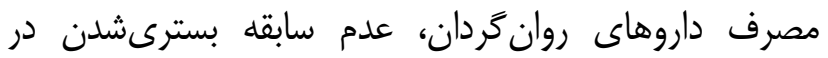
بيمارستان در دوران باردارى، دارابودن حداقل تحصيلات دروات

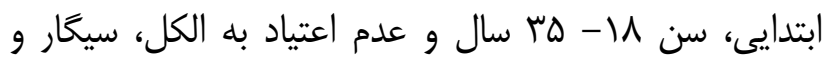

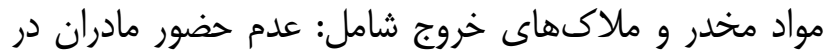
بيش از دو جلسه و عدم انجام تمرينات و تكاليف خانكى بود مداد

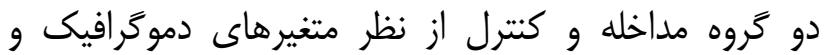
باردارى با هم يكسان بودند.

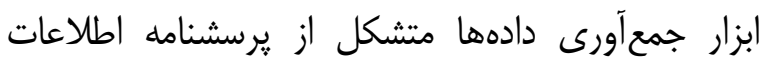
دموگرافيك (سن، تعداد حاملگى، نوع باردارى از نظر خواسته

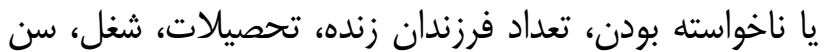

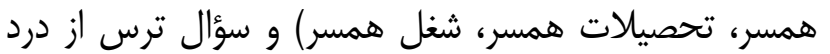

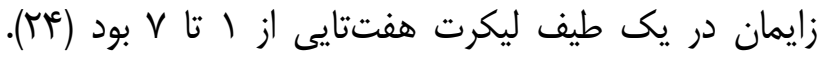

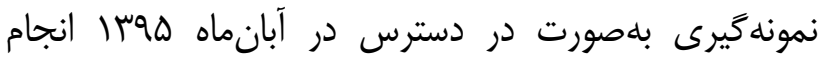
گرفت. بدينمنظور شهر اراك به هـ منطقه (شمال، جنوب،

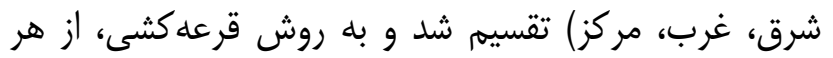

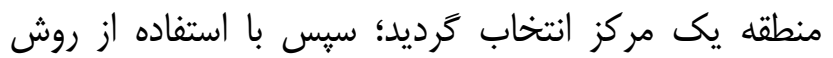

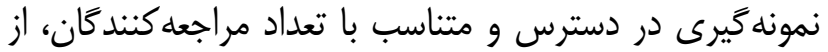

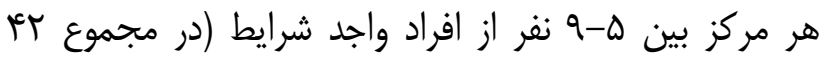

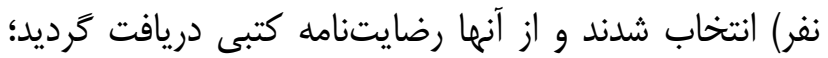

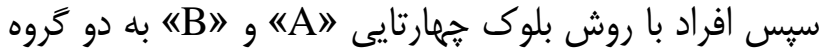


جدول I - يروتكل جلسات اكت در اضطراب زنان در دوران باردارى (ه ()

\begin{tabular}{|c|c|c|}
\hline محتواى جلسه & عنوان جلسه & جلسه \\
\hline 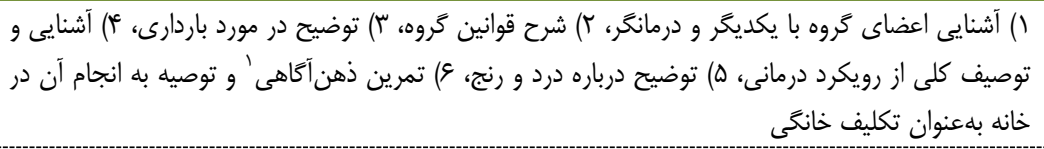 & خوشآمدَّويى و آشنايى با رويكرد & اول \\
\hline 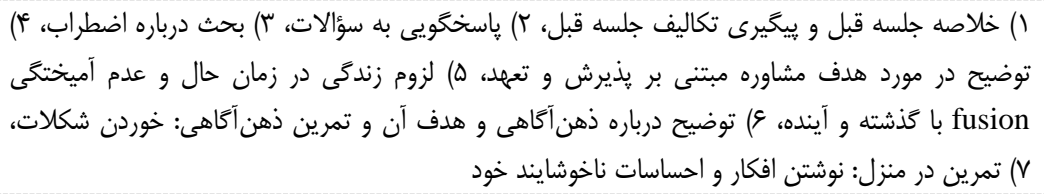 & زندگى در زمان حال و ذهن آَاهى & دوم \\
\hline 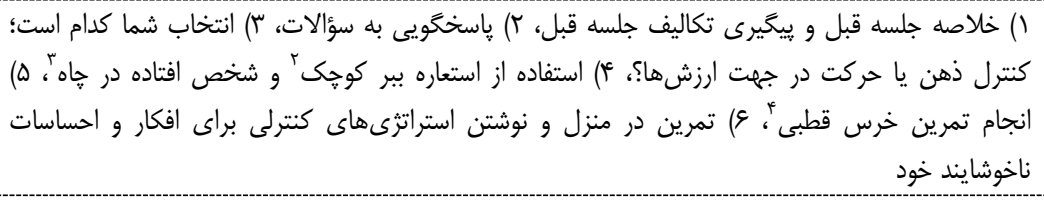 & اجتناب تجربهاى ه. & سوم \\
\hline 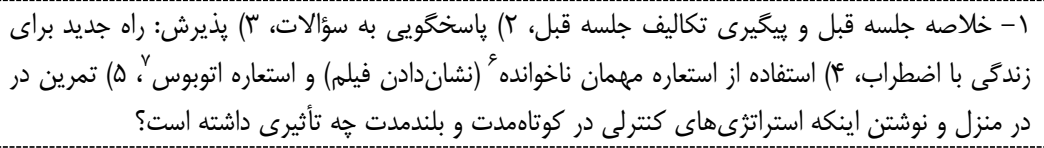 & يذيرش & جهارم \\
\hline 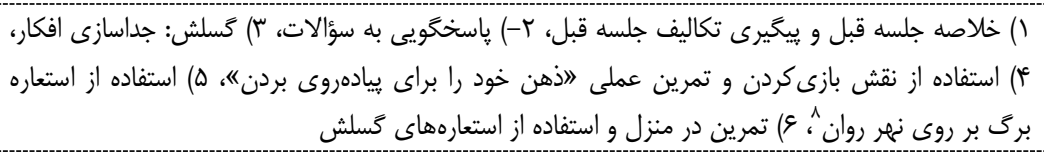 & كسلش & ينجم \\
\hline 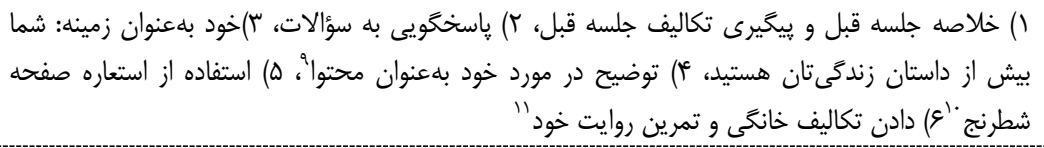 & خود بلعنوان زمينه & ششم \\
\hline 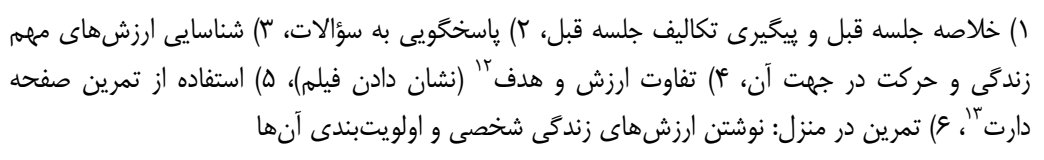 & ارزشها & هفتم \\
\hline 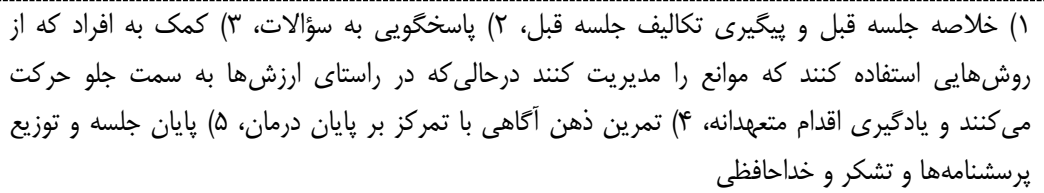 & اقدام متعهدانه & هشتم \\
\hline
\end{tabular}

\footnotetext{
${ }^{1}$ Mindfulness

${ }^{2}$ Little Tiger

${ }^{3}$ The fallen person in the hole

${ }^{4}$ Polar bear

${ }^{5}$ Experimental Avoidance

${ }^{6}$ Unwelcome Party Guest

${ }^{7}$ Bus metaphor

${ }^{8}$ Leaves on a Stream

${ }^{9}$ Self as content

${ }^{10}$ Chessboard Metaphor

${ }^{11}$ Self-narratives

12 Goals

${ }^{13}$ Bulls'-Eye
} 


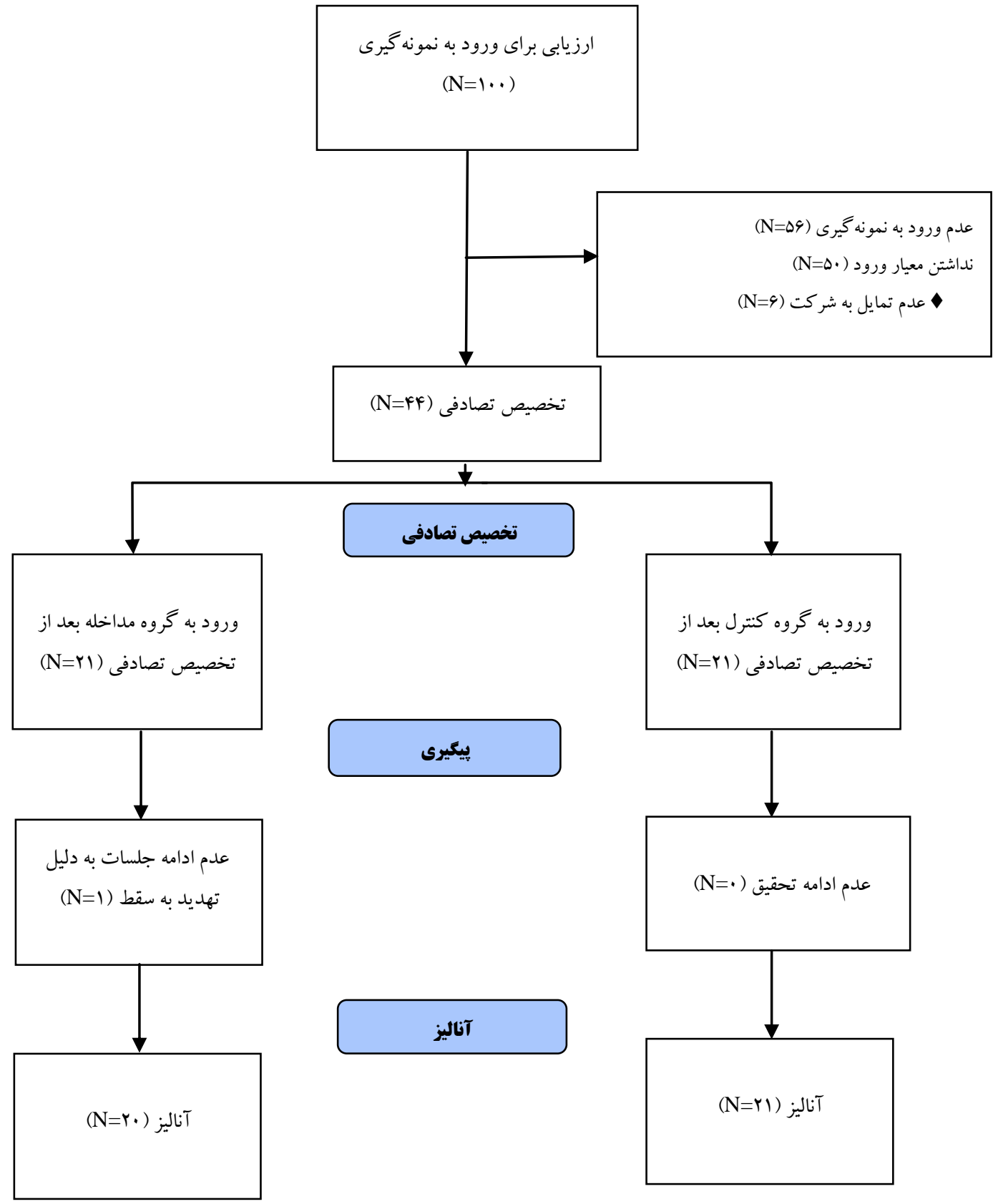

شكل ا - طراحى مطالعه در r كَروه كنترل و مداخله

دادههاى حاصل از يرسشنامه، با نرمافزار SPSS (ويرايش مربوط به شاخصها از نظر نرمالبودن بررسى گرديد و با

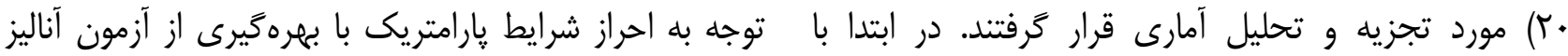

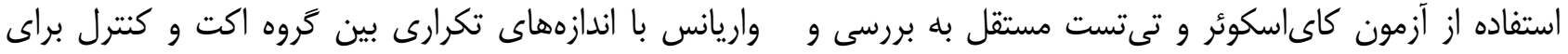

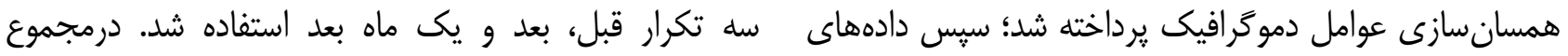




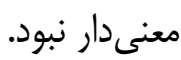

در مورد متغيّر ترس از درد زايمان، نتايج نشان داد كه اثر

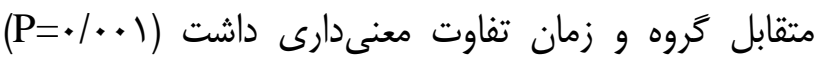

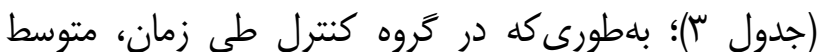
ترس از درد زايمان روند صعودى داشت، اما در گروه مداخله، ابتدا كاهش و سيس افزايش يافت؛ در هر دو نقطه زمانى (بعد روند مداخله و يك ماه بعد)، متوسط متغيّر ترس از درد زايمان در

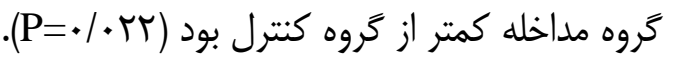

دادههاى مربوط به أب نفر از زنان باردار وارد تحليل شد.

\section{جدول r- ويزَّىهاى دموَّرافيك زنان باردار در ب تَروه مداخله و كنترل}

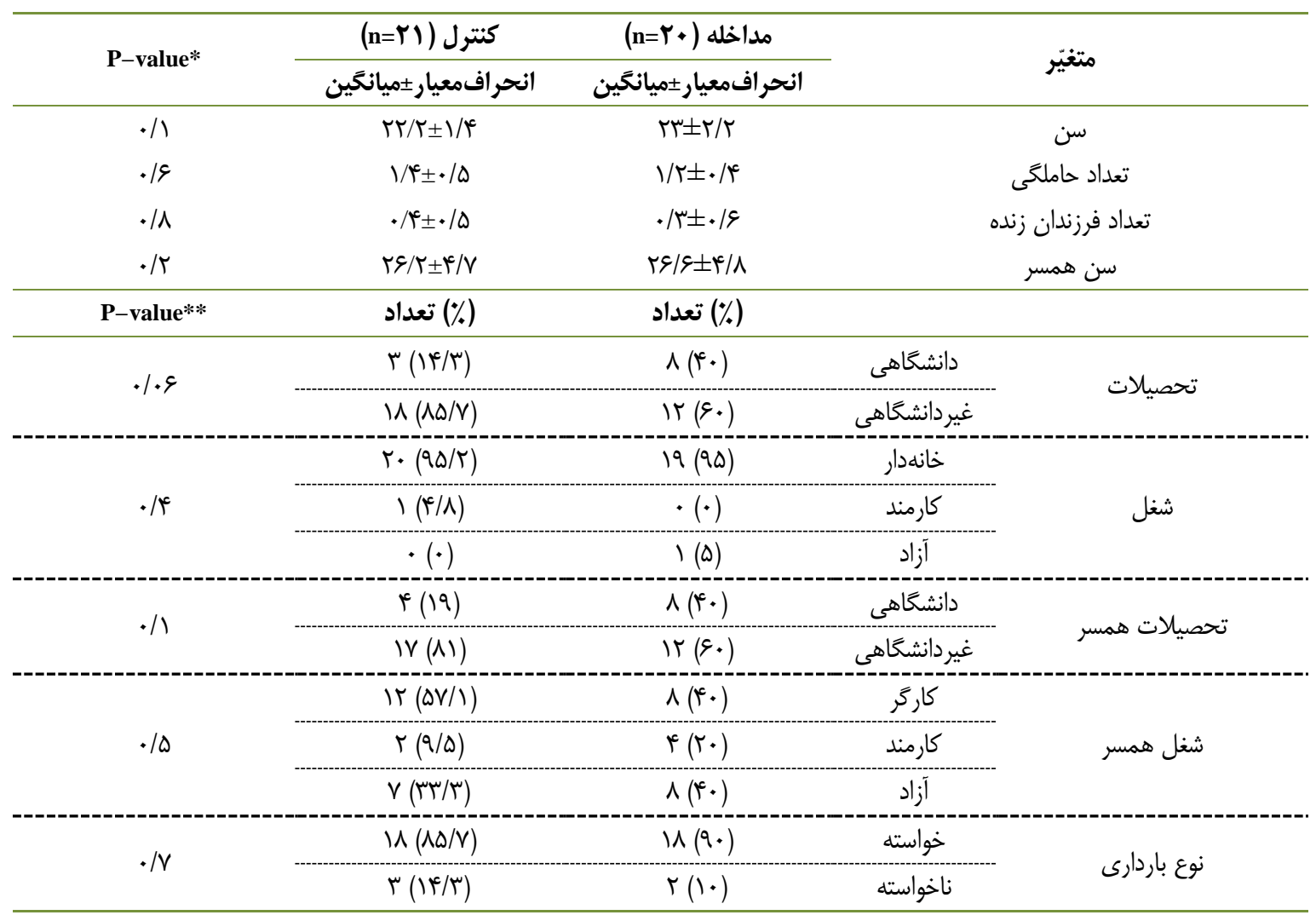

-T-test

$\bullet$ Chi-square 
جدول ؟ـ- مقايسه ميانَين ترس از درد زايمان در بَ كَروه مداخله و كنترل

\begin{tabular}{|c|c|c|c|c|c|c|}
\hline \multicolumn{3}{|c|}{ P-value } & \multirow{2}{*}{ انحر افمعيار } & \multirow{2}{*}{ ميانكَين } & \multirow{2}{*}{ تروه } & \multirow{2}{*}{ متغيّر } \\
\hline زمان & زمان تروه & تروه & & & & \\
\hline \multirow{9}{*}{$\cdot / \cdot v^{\mu}$} & \multirow{9}{*}{$.1 . .1$} & \multirow{9}{*}{.$/ . r T$} & $T / M F$ & $r / v$. & مداخله & \multirow{3}{*}{ ترس از درد قبل از } \\
\hline & & & $r / \mu$. & $r|q|$ & كنترل & \\
\hline & & & $T / T G$ & $\Gamma / 9 \Delta$ & كل & \\
\hline & & & $r / T$. & $T / Q T$ & مداخله & \multirow{3}{*}{ بعد از مداخله } \\
\hline & & & $1 / \Lambda r$ & $r / 99$ & كنترل & \\
\hline & & & $T / T \varphi$ & $r / V I$ & كل & \\
\hline & & & $1 / 11$ & T/DT & مداخله & \multirow{3}{*}{ يك ماه بعد } \\
\hline & & & $r / \mu$. & $F / \Delta T$ & كنترل & \\
\hline & & & $T / I F$ & $r / \cdot V$ & كل & \\
\hline
\end{tabular}

-ANOVA repeated measurement

باردارى كاهش مىدهد (TV). مطالعه حاضر به خانمهاى

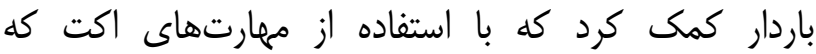

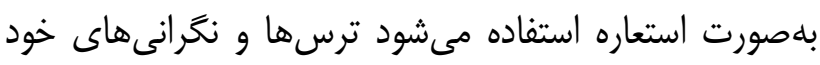

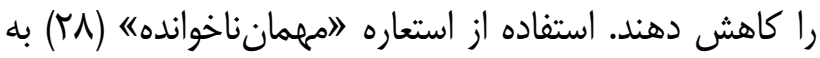

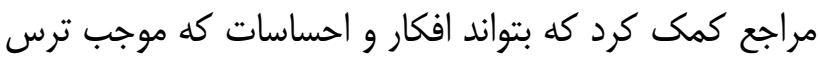

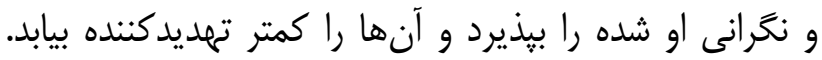

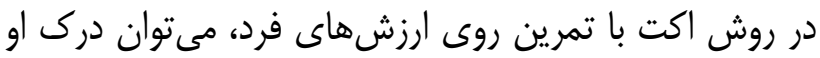

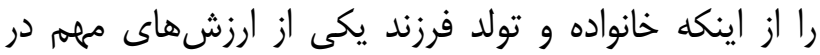

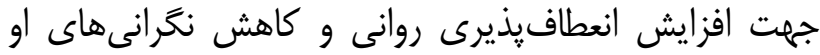
است تقويت كرد. مطالعducar كه با روش شناختى رفتارى روى ترس از زايمان انجام شد نشان داد كه با تغيير در

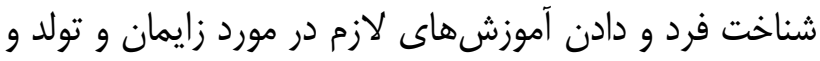

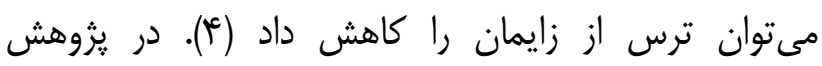
Rouhe

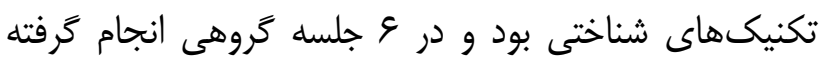
بود، موجب كاهش ترس از زايمان و سزارين انتخابى و

اورزانسى در زنان نخستزا شده بود (ج) (ب).

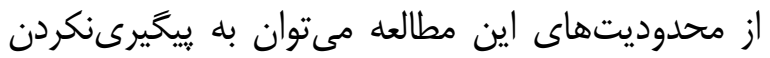

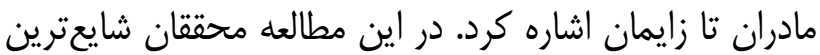

بر طبق نتايج اين مطالعه به نظر مىرسد ترس مادران از

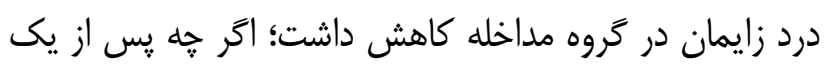

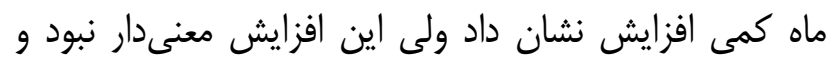

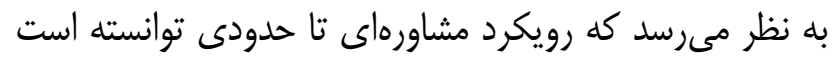

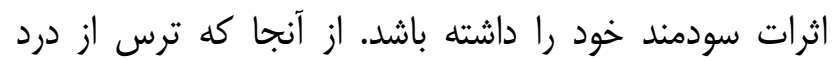
زايمان يكى از مهمترين دلايل زايمان سزارين در كشور ايران است (ז)؛ بنابراين به نظر مىرسد استفاده از اين روش مشاوره

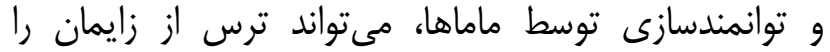

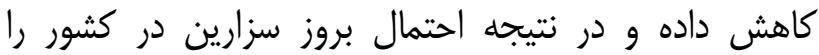

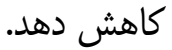
مطالعه وكيليان و همكاران با بررسى تأثير اكت روى

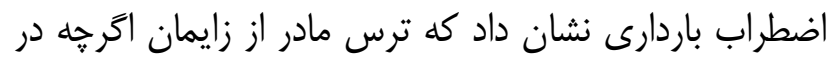

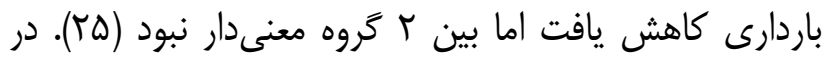

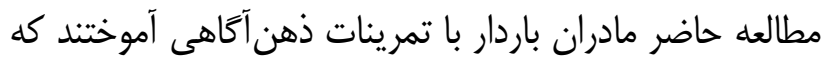
بر نخرش باز و كنجكاوى بر جنبههاى مختلف تجربdهايشان

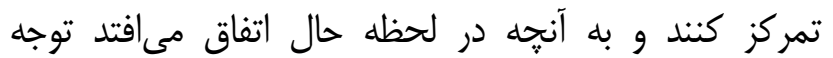

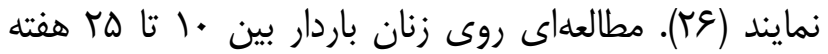
نشان داد كه ذهن آكاهى ميزان استرس و اضطراب زناب زنان ران دردان 


$$
\begin{aligned}
& \text { نخَرانى مادران را كه ترس از درد زايمان بود بررسى كردند. است و آنها بايد به سمت روشهاى با درد كمتر مثل سزارين }
\end{aligned}
$$

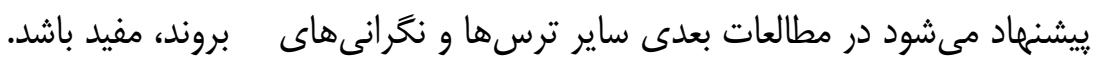

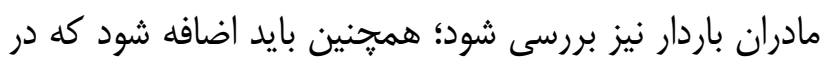

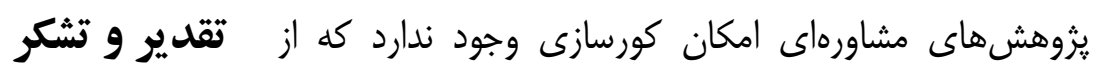

$$
\begin{aligned}
& \text { اين مطالعه منتج از يايان نامه كارشناسى ارشد مشاوره در }
\end{aligned}
$$

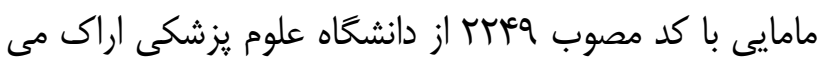

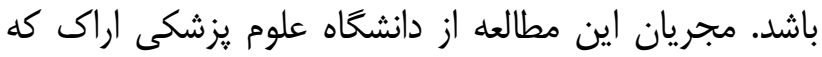

$$
\begin{aligned}
& \text { به نظر مىرسد مىتوان با استفاده از روشهاى نوين ما رادر اين يزوهش يارى كردند تشكر و قدردانى معى كنند. }
\end{aligned}
$$

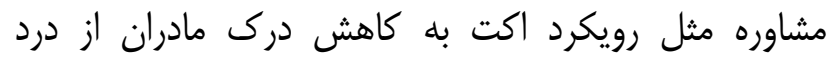

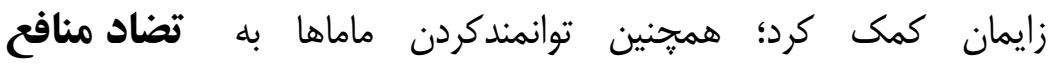

$$
\begin{aligned}
& \text { نويسندگان مقاله اعلام مىدارند كه هيج كونه } \\
& \text { منافعى در يزوهش حاضر وجود ندارد. } \\
& \text { رويكردهاى مشاورهاى مىتواند براى ارتقاى مراقبت از مادران }
\end{aligned}
$$

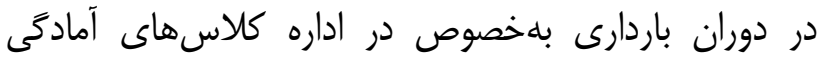

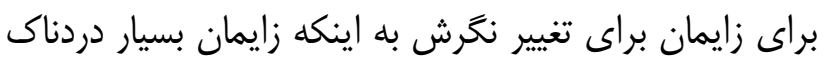

1- Parcells DA. Women's mental health nursing: depression, anxiety and stress during pregnancy. J Psychiatr Ment Health Nurs. 2010; 17(9): 813-20. doi: 10.1111/j.1365-2850.2010.01588.x.

2- Sadeghi R, Zareipour MA, Akbari H, Khan-Beygi M. Mental Health and associated factors amongst women referred to health care centers. Journal of Health And Care. 2011;13(4): 1-9. [Persian]

3- Nieminen K, Wijma K, Johansson S, Kinberger EK, Ryding EL, Andersson G, et al. Severe fear of childbirth indicates high perinatal costs for Swedish women giving birth to their first child. Acta Obstet Gynecol Scand. 2017; 96(4): 438-46. doi: 10.1111/aogs.13091.

4- Uçar T, Golbasi Z. Effect of an educational program based on cognitive behavioral techniques on fear of childbirth and the birth process. J Psychosom Obstet Gynaecol. 2019; 40(2):146-55. doi: 10.1080/0167482X.2018.1453800.

5- Khoursandi M, Vakilian K, Torabi Goudarzi M, Abdi M. Childbirth preparation using behavioral-cognitive skill in childbirth outcomes of primiparous women. J Babol Univ Med Sci. 2013; 15(4): 76-80. [Persian]

6- Poikkeus P, Saisto T, Unkila-Kallio L, Punamaki RL, Repokari L, Vilska S, et al. Fear of childbirth and pregnancyrelated anxiety in women conceiving with assisted reproduction. Obstet Gynecol. 2006; 108(1): 70-6. doi: 10.1097/01.AOG.0000222902.37120.2f.

7- Hajian S, Vakilian K, Shariati M, Ajami ME. Attitude of pregnant women, midwives, obstetricians and anesthesiologists toward mode of delivery: a qualitative study. Payesh. 2010; 10(1): 39-48. [Persian]

8- Khorsandi M, Vakilian K, Nasir zadeh Masooleh M. Investigating different factors of fear in normal delivery among pregnant women, in arak-a cross sectional study. J Fasa Univ Med Sci. 2014; 4(2): 161-7. [Persian]

Wijma K, Wijma B. A Woman Afraid to Deliver: How to Manage Childbirth Anxiety. In: Paarlberg K, van de Wiel H. (eds) Bio-Psycho-Social Obstetrics and Gynecology. Springer, Cham; 2017. pp: 3-31. doi:10.1007/978-3-31940404-2_1.

10- Fenwick J, Toohill J, Gamble J, Creedy DK, Buist A, Turkstra E, et al. Effects of a midwife psycho-education intervention to reduce childbirth fear on women's birth outcomes and postpartum psychological wellbeing. BMC pregnancy and childbirth. 2015; 15: 284. doi: 10.1186/s12884-015-0721-y

11- Dencker A, Nilsson C, Begley C, Jangsten E, Mollberg M, Patel H, et al. Causes and outcomes in studies of fear of childbirth: a systematic review. Women Birth. 2019; 32(2): 99-111. doi: 10.1016/j.wombi.2018.07.004. 
12- Cookson H, Granell R, Joinson C, Ben-Shlomo Y, Henderson AJ. Mothers' anxiety during pregnancy is associated with asthma in their children. J Allergy Clin Immunol. 2009; 123(4): 847-53. e11. doi: 10.1016/j.jaci.2009.01.042.

13- Daneshvar M, Vakilian K, Zadeh-Emran AH, Zadeh RH. The Effect of ACT on Self-Esteem and Self-efficacy of Women with Breast Cancer in Iran. Current Women's Health Reviews. 2020; 16(1): 74-80. doi: $10.2174 / 1573404815666191121150647$

14- Crosby JM, Twohig MP. Acceptance and Commitment Therapy for Problematic Internet Pornography Use: A Randomized Trial. Behav Ther. 2016; 47(3): 355-66. doi: 10.1016/j.beth.2016.02.001.

15- Eilenberg T, Fink P, Jensen J S, Rief W, Frostholm L. Acceptance and Commitment Group Therapy (ACT-G) for health anxiety- A randomized controlled trail. Dan Med J. 2016; 46(1): 103-15. doi: 10.1017/S0033291715001579

16- Swain J, Hancock K, Dixon A, Koo S, Bowman J. Acceptance and commitment therapy for anxious children and adolescents: study protocol for a randomized controlled trial. Trials. 2013; 14: 140. doi: 10.1186/1745-6215-14140.

17- Ivanova E, Lindner P, Ly KH, Dahlin M, Vernmark K, Andersson G, et al. Guided and unguided Acceptance and Commitment Therapy for social anxiety disorder and/or panic disorder provided via the Internet and a smartphone application: A randomized controlled trial. J Anxiety Disord. 2016; 44: 27-35. doi: 10.1016/j.janxdis.2016.09.012.

18- Arch JJ, Eifert GH, Davies C, Plumb Vilardaga JC, Rose RD, Craske MG. Randomized clinical trial of cognitive behavioral therapy (CBT) versus acceptance and commitment therapy (ACT) for mixed anxiety disorders. J Consult Clin Psychol. 2012; 80(5): 750-65. doi: 10.1037/a0028310.

19- Mohabbat-Bahar S, Maleki-Rizi F, Akbari ME, Moradi-Joo M. Effectiveness of group training based on acceptance and commitment therapy on anxiety and depression of women with breast cancer. Iran J Cancer Prev. 2015; 8(2): 71-6.

20- Yang SY, Moss-Morris R, McCracken LM. iACT-CEL: A Feasibility Trial of a Face-to-Face and Internet-Based Acceptance and Commitment Therapy Intervention for Chronic Pain in Singapore. Pain Res Treat. 2017; 2017: 6916915. doi: 10.1155/2017/6916915.

21- Parling T, Cernvall M, Ramklint M, Holmgren S, Ghaderi A. A randomised trial of Acceptance and Commitment Therapy for Anorexia Nervosa after daycare treatment, including five-year follow-up. BMC Psychiatry. 2016; 16: 272. doi: 10.1186/s12888-016-0975-6.

22- Eilenberg T, Hoffmann D, Jensen JS, Frostholm L. Intervening variables in group-based acceptance \&amp; commitment therapy for severe health anxiety. Behav Res Ther. 2017; 92: 24-31. doi: 10.1016/j.brat.2017.01.009.

23- Shin HS, Kim JH. Music Therapy on Anxiety, Stress and Maternal-fetal Attachment in Pregnant Women During Transvaginal Ultrasound. Asian Nurs Res (Korean Soc Nurs Sci). 2011; 5(1): 19-27. doi: 10.1016/S19761317(11)60010-8.

24- Vakilian K, Keramat A, Gharacheh M. Controlled breathing with or without lavender aromatherapy for labor pain at the first stage: A randomized clinical trial. Crescent J Med Biol Sci. 2018; 5(3): 172-5.

25- Vakilian K, Zarei F, Majidi A. Effect of Acceptance and Commitment Therapy (ACT) on Anxiety and Quality of Life During Pregnancy: A Mental Health Clinical Trial Study. Iran Red Crescent Med J. 2019; 21(8): e89489. doi: 10.5812/ircmj.89489.

26- Dunn C, Hanieh E, Roberts R, Powrie R. Mindful pregnancy and childbirth: effects of a mindfulness-based intervention on women's psychological distress and well-being in the perinatal period. Arch Womens Ment Health. 2012; 15(2): 139-43. doi: 10.1007/s00737-012-0264-4.

27- Guardino CM, Dunkel Schetter C, Bower JE, Lu MC, Smalley SL. Randomised controlled pilot trial of mindfulness training for stress reduction during pregnancy. Psychol Health. 2014; 29(3): 334-49. doi: 10.1080/08870446.2013.852670.

28- Hayes S, Strosahl K, Wilson K. Acceptance and commitment therapy: The process and practice of mindful change. $2^{\text {nd }}$ ed. New York: The Guilford Press; 2012.

29- Rouhe H, Salmela-Aro K, Toivanen R, Tokola M, Halmesmäki E, Saisto T. Obstetric outcome after intervention for severe fear of childbirth in nulliparous women-randomised trial. BJOG. 2013; 120(1): 75-84. doi: 10.1111/14710528.12011 . 